Ambiente \& Água - An Interdisciplinary Journal of Applied Science
ISSN 1980-993X - doi:10.4136/1980-993X
www.ambi-agua.net
E-mail: ambi-agua@agro.unitau.br

\title{
Visitação em parques insulares: indicadores como ferramenta de gestão
}

\author{
doi: 10.4136/ambi-agua.1370
}

Received: 16 Aug. 2013; Accepted: 08 Dec. 2013

\author{
Ginessa Corrêa Lemos ${ }^{1}$; Getulio Teixeira Batista ${ }^{2}$; Maria de Jesus Robim $^{3}$ \\ ${ }^{1}$ Programa de Pós-graduação em Ciências Ambientais da UNITAU \\ ${ }^{2}$ Universidade de Taubaté (UNITAU), Taubaté-SP, Brasil \\ ${ }^{3}$ Instituto Florestal, São Paulo-SP, Brasil \\ *Autor correspondente: e-mail: getulio@agro.unitau.br, \\ ginessacl@gmail.com,mjesusrobim@gmail.com
}

\section{RESUMO}

A visitação em parques tem aumentado a cada ano, contudo as unidades de conservação, em sua maioria, não apresenta estrutura administrativa adequada e capacitada para fazer a gestão da visitação, especialmente quando se trata de ambientes insulares. O Parque Estadual de Ilhabela (PEIb) é um exemplo dessa situação, por isso foi selecionado para esta pesquisa, que teve por objetivo identificar indicadores para a gestão da visitação no parque. Para tanto, utilizou-se como referência a proposta de indicadores do Bountîle - Base de observação de usos náutico e terrestre em ilhas, desenvolvida por pesquisadores franceses para o Parque Nacional de Port-Cros, na França. O estudo apresenta duas etapas principais. A primeira, denominada de estudo da visitação, que buscou reunir informações e caracterizar a visitação. Já a segunda etapa foi a escolha de indicadores de gestão. Foram referências a proposta do WWF BRASIL (2004) e Tonge et al. (2005), da Austrália, que possibilitaram identificar os indicadores mais adequados e necessários a serem monitorados no PEIb. Dentre os resultados do estudo da visitação foram diagnosticados: o perfil dos visitantes, tipos de atividades realizadas, conflitos de uso e períodos de maior fluxo por atrativo oficial. Com base na análise da visitação no PEIb foram definidos 20 indicadores de gestão, a partir dos seguintes critérios: usos e usuários; condições climáticas; bem-estar dos moradores; segurança; perfil do visitante; bem-estar do visitante; comportamento do visitante; certificação; e, gestão e integração institucional. A diversidade dos critérios consistiu no principal resultado, pois dessa forma foi possível abranger os diversos aspectos necessários para a gestão da visitação em uma unidade de conservação. Os indicadores são flexíveis, podendo ser mudados a qualquer tempo, para que estejam sempre em harmonia com os objetivos de gestão e com indicações do plano de manejo. Devem ainda ser viáveis econômica, técnica e operacionalmente, e discutidos e testados com os funcionários do parque e atores locais, garantindo assim o monitoramento contínuo e a eficiência do sistema de gestão da visitação.

Palavras-chave: gestão da visitação, indicadores, Parque Estadual de Ilhabela.

\section{Visitation in island parks: indicators as a tool for management}

\section{ABSTRACT}

Park visitation has been increasing every year; however, the majority of the protected areas have no satisfactory and qualified administrative structure to control visitation, especially when island ecosystems are considered. The State Park of Ilhabela (PEIb) is a good 
example of this, and was therefore selected for this study, which hoped to identify indicators for better management of park visitation. In order to select indicators to be used as a reference for this purpose, this study employed the Bountîle - Base of observation for nautical and terrestrial purposes within islands - developed by French researchers for the National Park of Port-Cros, and complemented this with guidelines from the Brazilian Ministry of Environment and other authors. These led to the selection of the following indicators: a) opportunities of recreation for a diverse public; b) visitation security; c) satisfaction with the experience; d) minimal environmental impact; e) spinoff of socioeconomic development of the surrounding community. Based on the PEIb analyses, 20 management indicators were identified using the following criteria: uses and users; climatic conditions; well-being of the residents; security; profile of the visitor; well-being of the visitors; behavior of the visitors; certification, management, and institutional integration. The criteria of the indicators is greatly diversified, as it is believed that such diversity is essential to encompass the varied aspects that must be considered by a visitation management system in a conservation area. The indicators are flexible, and can be changed anytime, so that they will always be in harmony with the goals of the park management plan. In order to be efficient, they should be feasible economically, technically, and operationally. It is essential that indicators and protocols be discussed and tested with park workers and local actors, ensuring active management and continuous monitoring.

Keywords: visitation management, indicators, State Park of Ilhabela.

\section{INTRODUÇÃOO}

Uma importante alternativa para a proteção das áreas naturais é a criação de unidades de conservação da natureza. Essas áreas de proteção se espalharam por todo o mundo e, devido à riqueza natural de seus espaços, passaram a atrair a atenção de visitantes, dentre eles os chamados ecoturistas.

No Brasil, o turismo nas unidades de conservação iniciou oficialmente na década de 80 do século passado, ganhando força econômica a partir de 1990. No ano 2000 foi aprovada a Lei 9.985, que instituiu o SNUC - Sistema Nacional de Unidades de Conservação, que visa ordenar a criação e gestão das unidades de conservação no país. É esse documento que institui a categoria de unidades de conservação, na qual se classificam os parques, que tem como objetivos a recreação, a educação ambiental e o turismo ecológico, contribuindo definitivamente para o futuro promissor do turismo nessas áreas.

Atualmente, as UCs gerenciadas pelo Instituto Chico Mendes de Conservação da Biodiversidade (ICMBio) estão em torno de 300, todas criadas e regidas pelo Sistema Nacional de Unidades de Conservação (SNUC), Lei Federal criada em 2000 (Brasil, 2004). Das 67 unidades de conservação brasileiras que são parques nacionais, 31 estão abertas à visitação e tiveram mais de $50 \%$ de aumento no número de visitas nos últimos quatro anos (Figura 1) (Brasil, 2009).

No estado de São Paulo são 70 Unidades de Conservação da Natureza, sendo 50 gerenciadas pela Fundação Florestal, 17 gerenciadas pelo Instituto Florestal e três gerenciadas pelo Instituto de Botânica, órgãos da Secretaria Estadual de Meio Ambiente - SMA. Dessas unidades, 33 são Parques Estaduais (São Paulo, 2012). A demanda por diversas formas de lazer e esporte em contato com a natureza tem crescido nessas UCs paulistas, com atividades terrestres, aquáticas, aéreas e em cavernas (São Paulo, 2009).

Vários fatores contribuem para o acelerado crescimento desse segmento do turismo, dentre eles o fato de o ambientalismo ter-se tornado uma tendência e até modismo, a partir da década de 80. Junto a esse fator soma-se a fuga do cotidiano estressante das sociedades urbanas, que leva os indivíduos a buscarem o contato com a natureza. 
Contudo, apesar das práticas de recreação nos parques ser permitida, em alguns casos entram em conflito com os objetivos da conservação. Assim, são necessários estudos e medidas que busquem maneiras de evitá-los e resolvê-los (Kabashima e Magro, 2011). Para tanto, é preciso haver o planejamento e gestão dessas atividades, de maneira que abranjam toda a sua complexidade, minimizando os efeitos negativos e potencializando os positivos.

Para as UCs que realizam a cobrança de taxas de entrada, a renda gerada pela visitação é revertida para investimentos na própria unidade, sustentando outros setores, além do Uso Público. Além disso, Takahashi (2006) sugere que as visitas sejam estimuladas em UCs que apresentam atrativos para arrecadar recursos que poderiam ser usados em outras unidades não tão atrativas, para aumentar benefícios sociais e culturais e a permanência de visitantes na região.

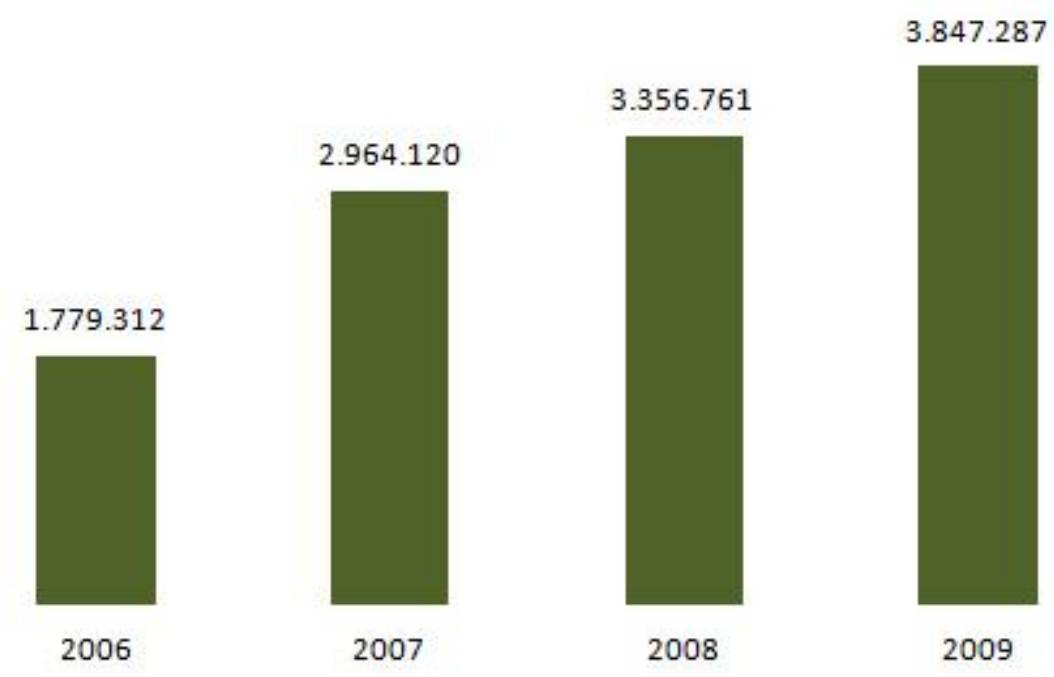

Figura1. Número de visitantes nos parques nacionais brasileiros.

Fonte: Adaptado de ICMBio (2009).

Apesar das estatísticas favoráveis que enaltecem a grandiosidade do ecoturismo nas áreas protegidas e sua importância para o fomento do conceito de sustentabilidade, instrumentos de manejo e regulatórios, como o caso dos Planos de Manejo e Planos de Uso Público, são inexistentes ou desatualizados em grande parte das Unidades de Conservação abertas à visitação pública. Embora seja evidente que a visitação desordenada resulta em efeitos negativos para as áreas, muitos deles podem ser minimizados ou até evitados, se manejados adequadamente. Para Takahashi (2006), os principais envolvidos nas UCs é que estão em posição de julgar os efeitos da visitação, determinando o quanto são aceitáveis e sugerindo como pode ser feito o manejo e a gestão. Ressalte-se que encontrar o equilíbrio em "como" atender a demanda existente e crescente sem que ocorra a degradação dos ambientes representa o maior desafio dos dias atuais aos pesquisadores e administradores dessas áreas.

Stigliano e César (2008) consideram que a necessidade de desenvolvimento de modelos e instrumentos para monitorar e gerenciar a visitação em áreas naturais tem-se tornado imperiosa, enquanto a literatura sobre essas questões continua carente. Independentemente do instrumento ou método adotado pela gestão da UC, ter informações sobre o tipo de uso, quem são visitantes e quais os objetivos de manejo são pré-requisitos indispensáveis. Estudos que identifiquem a percepção do visitante em relação ao ambiente visitado, principalmente em relação às condições ecológicas, e informações sobre o ambiente visitado, também representam uma grande contribuição para subsidiar a tomada de decisão.

O Parque Estadual de Ilhabela (PEIb) é administrado pela Fundação para Conservação, e a Produção Florestal do Estado de São Paulo (FF) possui 27.025 hectares e abrange 12 ilhas, dois ilhotes e duas lajes, tombados pelo CONDEPHAAT. Reconhecido pela UNESCO como Núcleo da Reserva da Biosfera da Mata Atlântica, apresenta-se como um dos principais 
atrativos de Ilhabela e é responsável pela proteção de cerca de $80 \%$ do território do município. Entretanto, por apresentar uma extensa área, falta de recursos e inexistência de plano de manejo, dentre outros fatores, não consegue direcionar e ter o controle da visitação em seus atrativos.

Assim, este trabalho tem por objetivo identificar indicadores para a gestão da visitação no Parque Estadual de Ilhabela (PEIb).

\section{MATERIAL E MÉTODO}

A proposta apresentada por Brigand e Le Berre (2007) para o Parque Nacional de PortCros (PNPC), na França, foi usada como base para a proposta de gestão da visitação no Parque Estadual de Ilhabela, devido às semelhanças entre eles. Trata-se de um sistema, composto de 04 etapas complementares, conforme ilustra a Figura 2.

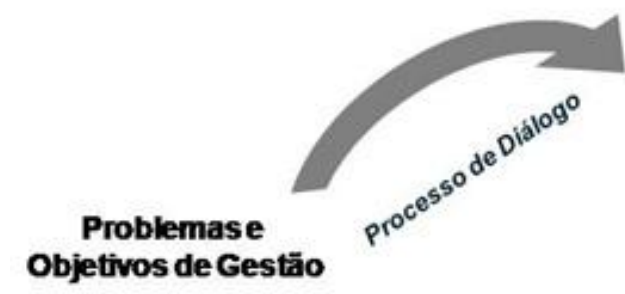

Tomadade Decisăo

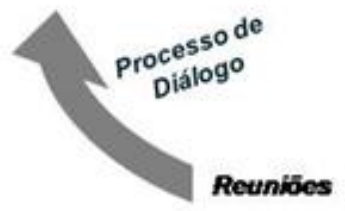

PGbicicas
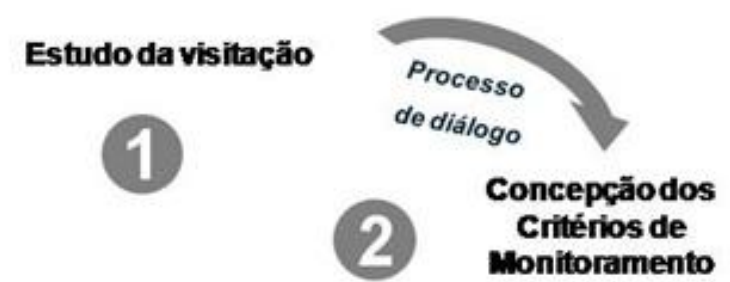

Monitoramento

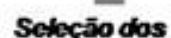

indicadores
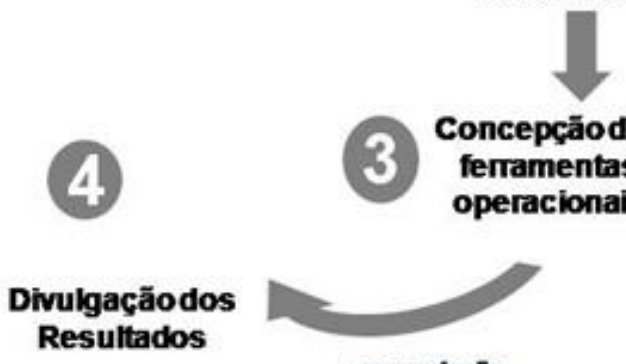

Divulgaçãodos
Resultados

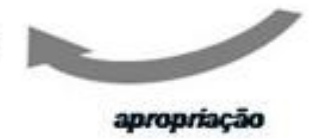

Figura 2. Etapas da construção do Bountîle no Parque Nacional de Port-Cros.

Fonte: Adaptado de Brigand e Le Berre (2007).

$\mathrm{Na}$ primeira etapa do estudo da visitação foram utilizadas abordagens qualitativa e quantitativa para a caracterização da visitação no parque, como mostra a Figura 3. Essa etapa foi fundamental para a seleção posterior de indicadores de gestão da visitação.

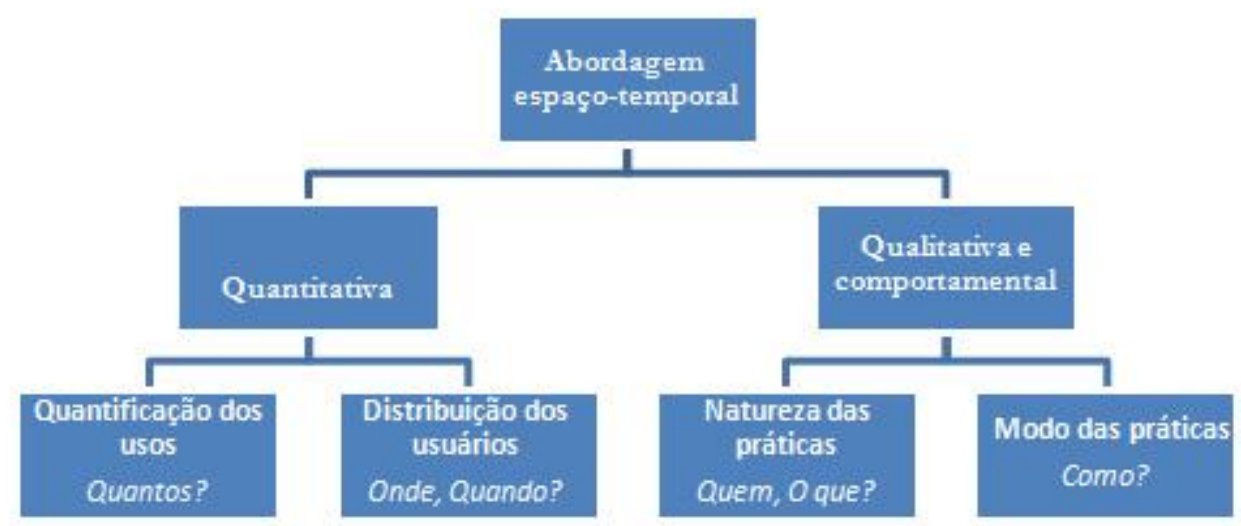

Figura 3. Estudo da visitação: princípios metodológicos.

Fonte: Adaptado de Brigand e Le Berre (2007). 
Foram coletadas informações sobre fluxos de turismo em Ilhabela e no Parque, nos documentos: Plano Gestor de Turismo de Ilhabela (T4 Consultoria em Turismo, 2004), Diagnósticos e relatórios produzidos pelas contratações do Projeto de Ecoturismo na Mata Atlântica, Registros da Dersa (operadora da balsa) e arquivos da Secretaria de Turismo e Fomento de Ilhabela, e, principalmente, os arquivos de visitação do Parque Estadual de Ilhabela, registrados pelo Programa de Uso Público por meio de tabelas de número de visitantes, fichas de controle e análise da tabulação dos questionários aplicados.

$\mathrm{Na}$ aplicação dos questionários foram selecionados aleatoriamente 93 indivíduos maiores de 18 anos, para responder a questões sobre sua visita ao parque, no momento em que saíam da trilha. Os questionários contendo 14 perguntas foram aplicados simultaneamente em 3 atrativos oficiais - Trilha da Água Branca, Trilha do Veloso e Trilha dos Três Tombos - no período de 21, 22 e 23 de abril, entre 09 e 16h. Considerou-se o período de feriado prolongado, em que o fluxo de visitantes é tão alto quanto na temporada de verão. Contou-se com a colaboração dos monitores do parque e voluntários.

Para identificação dos dados da frequentação náutica, que se refere à presença de embarcações e visitantes em áreas marinhas que dão acesso a área do PEIb, foram coletadas informações nas marinas e operadoras de mergulho.

$\mathrm{Na}$ segunda etapa, foram identificados e selecionados os indicadores de gestão. Para tanto, além dos indicadores utilizados no Bountîle, também foram usados como referência alguns indicadores do Manual de Turismo Responsável para Políticas Locais, produzido pelo WWF Brasil (2004). Nesse sentido, foram propostos indicadores para monitorar e avaliar o processo de desenvolvimento do turismo e a sustentabilidade da atividade nessas áreas, com base no conceito da sustentabilidade dos chamados indicadores de gestão do turismo responsável, classificados em indicadores de gestão, econômicos, sociais e ambientais.

\section{RESULTADOS E DISCUSSÃO}

A característica mais significativa do parque é o seu caráter insular. Sendo um parquearquipélago, abrange 12 ilhas, dois ilhotes e duas lajes, sendo uma área tombada pelo CONDEPHAAT e reconhecida pela UNESCO como Núcleo da Reserva da Biosfera da Mata Atlântica. Além disso, das 18 comunidades tradicionais caiçaras da ilha, cinco estão inseridas no perímetro do Parque, até que alguma medida governamental regularize a ocupação, já que a categoria Parque não permite moradores em seu interior.

Atualmente o PEIb tem, dentre seus atrativos oficiais, seis trilhas - Trilha da Água Branca, Três Tombos, Veloso, Baepi, Bonete e Gato - e a Estrada Parque dos Castelhanos. Os atrativos constituem-se em trilhas que recortam a mata atlântica e levam os visitantes a poços naturais, cachoeiras, mirantes, pico e praia. Estão espacialmente distribuídos em diferentes locais da Ilha de São Sebastião.

Estima-se que o PEIb recebe mais de 150 mil visitantes ao ano, conforme dados apresentados no Plano Gestor de Turismo de Ilhabela (T4 Consultoria em Turismo, 2004). Contudo, esse número vai muito além das contagens realizadas pelo parque, que chegam a um máximo de 50 mil visitantes ao ano.

O controle e a contagem dos visitantes são grandes desafios para a gestão do programa. A dinâmica descentralizada dos atrativos e a falta de recursos físicos e de funcionários impedem, até o momento, um controle integral e efetivo dos visitantes. Portanto, não existem dados que mostrem a plenitude da visitação aos atrativos do parque. Os arquivos disponibilizados para análise mostraram que a contagem é feita de acordo com as possibilidades do momento.

Em 2009 e 2010 e na temporada de 2010-2011, o programa de visitação já se encontrava mais bem estruturado, o que tornou possível levantar dados sobre o número de visitantes em 
determinados períodos desses anos. A Figura 4 mostra o número de visitantes dos anos de 2009 e 2010.

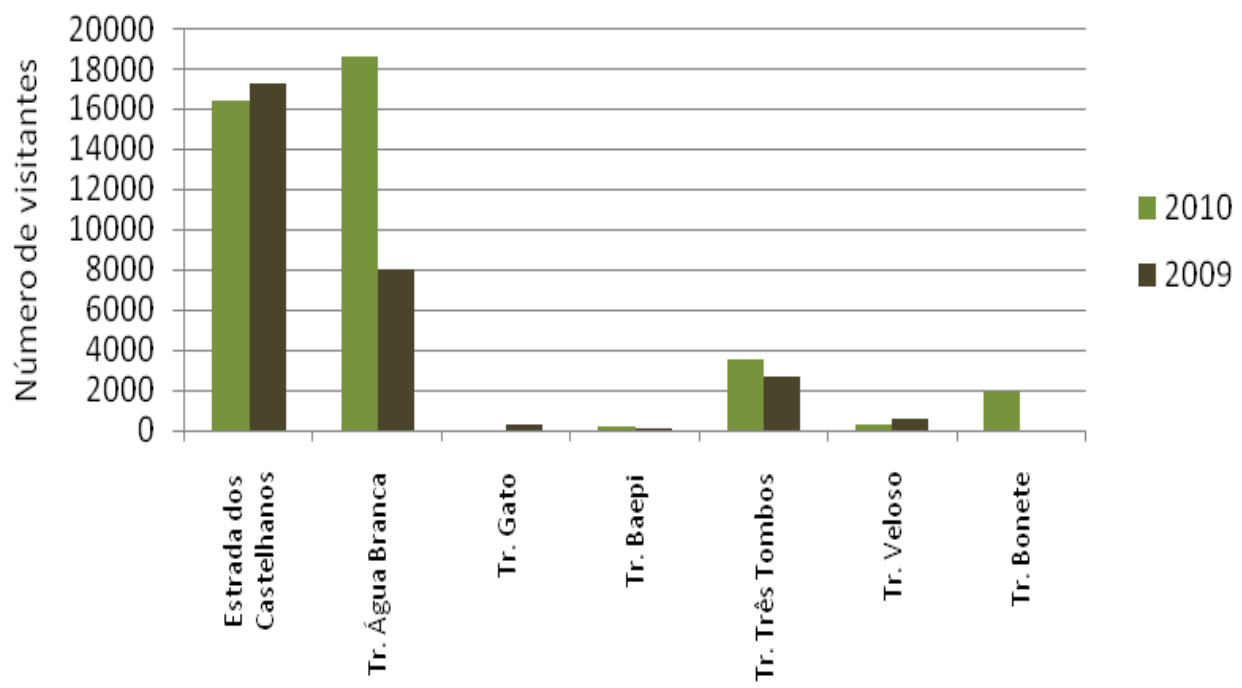

Figura 4. Número de visitantes por atrativo registrado pelo Parque Estadual de Ilhabela (PEIb) em 2009 e 2010. (Tr.=trilha).

Verifica-se, na Figura 5, que o maior fluxo de visitantes refere-se ao período da temporada de verão, nos meses de dezembro, janeiro e fevereiro, período de maior movimento de turistas na ilha. A temporada 2009-2010 representou 54\% da visitação do ano de 2010. Observa-se ainda que os meses de abril, setembro e novembro mostram valores maiores dos que os dos outros meses, supostamente devido aos feriados prolongados que marcam esses meses. Entre os meses de março a novembro, incluem-se aos números de visitantes as visitas de grupos de escolares.

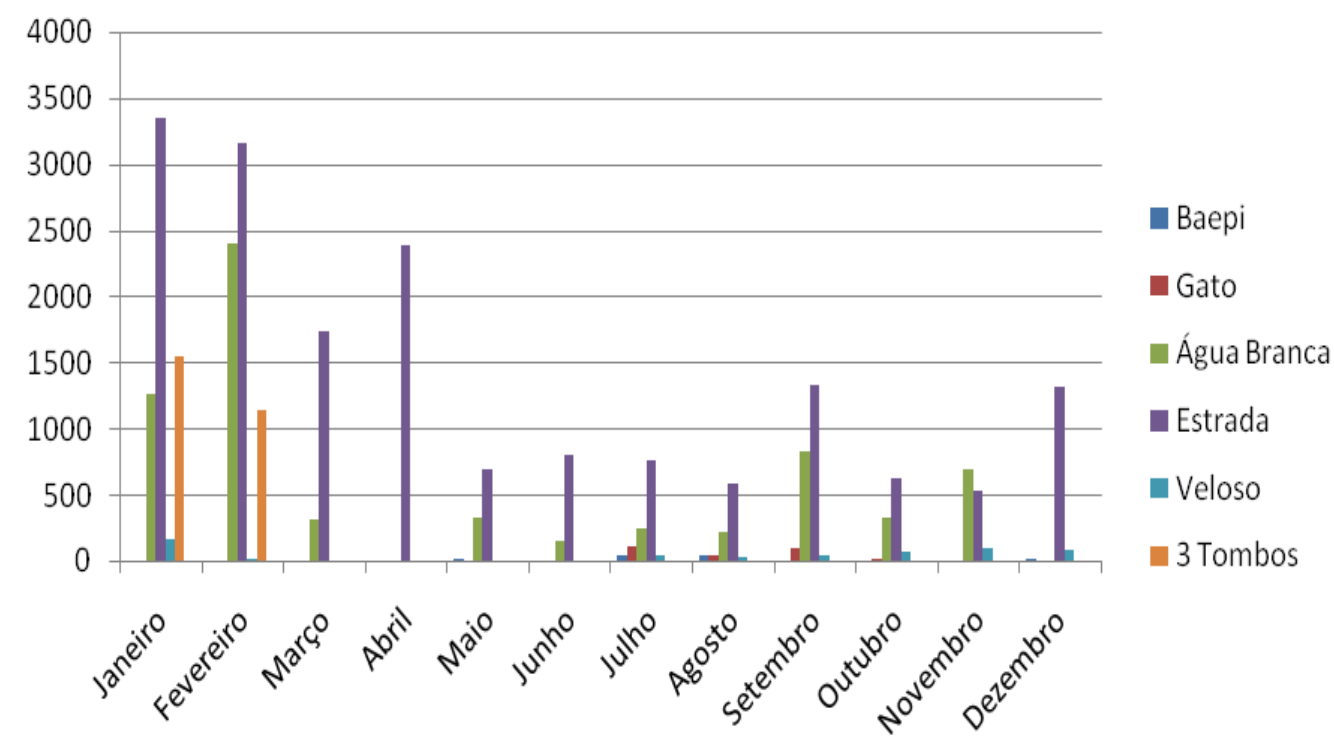

Figura 5. Número de visitantes nas trilhas registrado pelo Parque Estadual de Ilhabela (PEIb), por mês, em 2009.

\subsection{Visitação em áreas terrestres, costeiras e marinhas do PEIb}

A dificuldade para controlar o número de visitantes é ainda maior, nos locais com acesso direto por mar, como o saco do Sombrio, praia da Figueira, ilhas da Vitória e dos 
Búzios, situados na cota zero. Embora inteiramente na área do PEIb, esses locais têm seu acesso exclusivamente marítimo, em áreas da APA Marinha Litoral Norte - Setor Maembipe.

Apesar de a maioria dos usos da visitação náutica ser na área marinha, em alguns poucos casos os visitantes acessam as áreas terrestres. O Saco do Sombrio recebe turistas, devido à base do Iate Clube instalada no local, que oferece um espaço de lazer com píer e restaurante. Assim, os visitantes ficam restritos a essa estrutura disponibilizada.

A Figura 6 mostra que, segundo os registros das marinas colaboradoras, anualmente o local chega a receber mais de 1300 pessoas, sendo responsável por $85 \%$ de todo o fluxo náutico da costa oceânica da ilha. As ilhas da Vitória e dos Búzios recebem diariamente, em seu entorno, barcos de pesca, tanto amadora quanto profissional, e mergulhadores, devido aos pontos de mergulho localizados na área da APA Marinha Litoral Norte. Contudo, nesses locais os turistas não chegam a ter acesso às áreas terrestres.

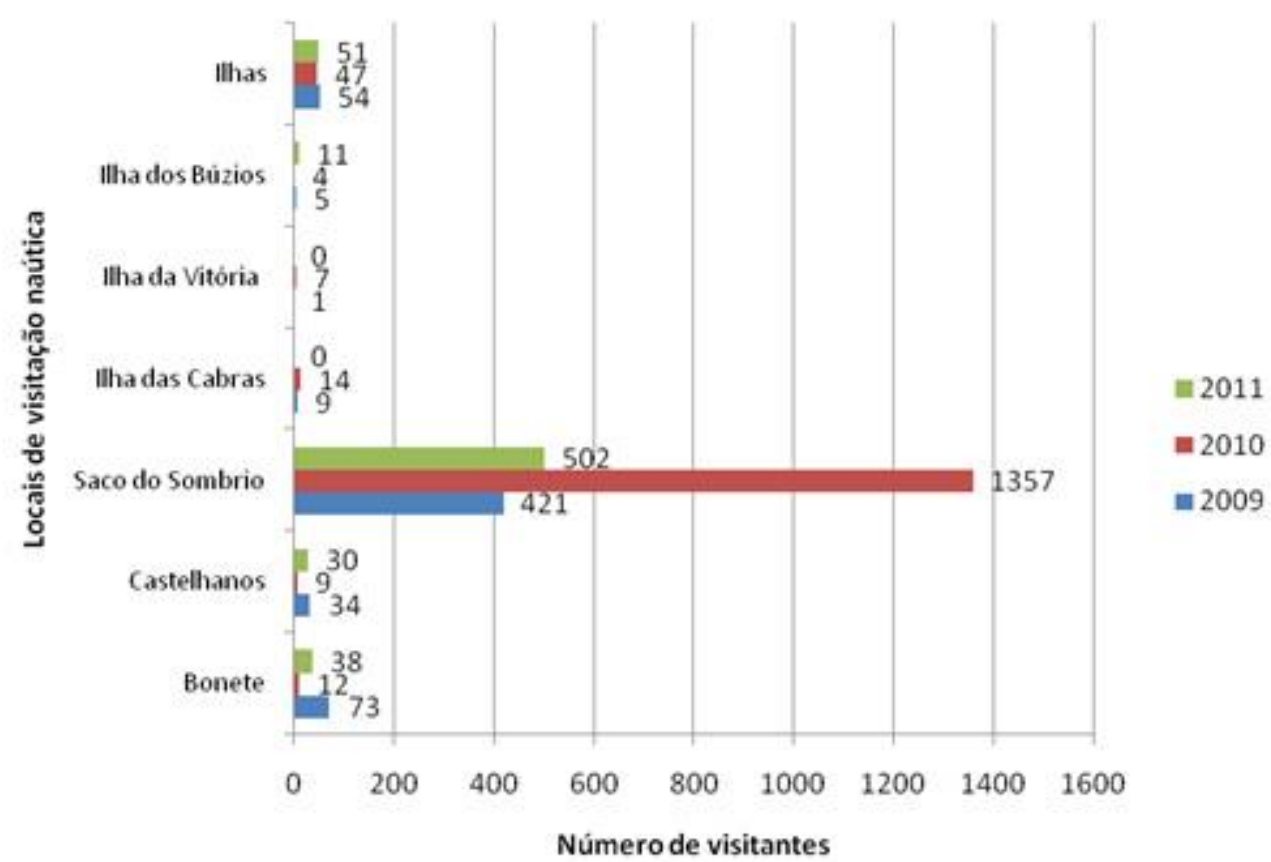

Figura 6. Número de visitação náutica aos diversos locais turísticos de Ilhabela, nos anos de 2009, 2010 e 2011.

Segundo os registros, do total de saídas registradas pelas três marinas, o Bonete recebe 4\% dos visitantes, e Castelhanos, 3\%. Outros locais em área do PEIb foram identificados nos registros de visitação náutica como a ponta do Boi e a ilha das Cabras. De forma geral, a visitação nas áreas selecionadas caracteriza-se de acordo com a Tabela 1.

Tabela 1. Caracterização da frequentação náutica.

\begin{tabular}{|c|c|c|c|c|}
\hline \multicolumn{2}{|c|}{ Onde } & O que & Quando & Quem \\
\hline $\begin{array}{l}\text { Ilha da } \\
\text { Vitória }\end{array}$ & $\begin{array}{c}\text { APA } \\
\text { Marinha }\end{array}$ & Mergulho & $\begin{array}{l}\text { Temporada/ Fins } \\
\text { de Semana }\end{array}$ & $\begin{array}{c}\text { Operadoras } \\
\text { Ilhabela/Ubatuba }\end{array}$ \\
\hline $\begin{array}{l}\text { Ilha dos } \\
\text { Búzios }\end{array}$ & $\begin{array}{c}\text { APA } \\
\text { Marinha }\end{array}$ & Mergulho & $\begin{array}{c}\text { Temporada/ Fins } \\
\text { de Semana }\end{array}$ & $\begin{array}{c}\text { Operadoras } \\
\text { Ilhabela/Ubatuba }\end{array}$ \\
\hline $\begin{array}{l}\text { Praia da } \\
\text { Figueira }\end{array}$ & PEIb & Pesca, praia & $\begin{array}{c}\text { Temporada/ Fins } \\
\text { de Semana }\end{array}$ & $\begin{array}{c}\text { Poucas embarcações } \\
\text { particulares }\end{array}$ \\
\hline $\begin{array}{l}\text { Saco do } \\
\text { Sombrio }\end{array}$ & PEIb & Pesca/restaurante & $\begin{array}{l}\text { Temporada/ Fins } \\
\text { de Semana }\end{array}$ & $\begin{array}{c}\text { Associações de } \\
\text { embarcações } \\
\text { particulares }\end{array}$ \\
\hline
\end{tabular}


Sabe-se que atividades de turismo nesses locais geram alguns conflitos. Além de serem áreas das comunidades tradicionais, abrangem o Parque Estadual de Ilhabela e a APA Marinha Litoral Norte, cujos usos são bastante restritos. Por isso, é extremamente importante que a atividade náutica seja incluída no estudo da visitação do PEIb. Assim, ficará possível fazer o monitoramento e estabelecer medidas de gestão que evitem conflitos sociais e ambientais e garantam a qualidade da experiência dos visitantes desse segmento.

O estudo da visitação dos usos terrestres no PEIb confirma que a variedade de atrativos e opções de recreação oferecidas pelo seu potencial natural atrai um público de perfil bastante diversificado. Tal constatação ficou evidente na análise feita por trilhas, em que foi possível identificar detalhes do perfil e práticas dos visitantes. A Tabela 2 mostra um panorama geral da visitação no PEIb.

Dos 93 visitantes entrevistados, 59\% são da cidade de São Paulo, e os demais se dividem entre cidades do interior do estado, principalmente grande São Paulo e vale do Paraíba. Também foi registrada a presença de visitantes dos estados do Paraná, Santa Catarina e Distrito Federal. Não houve registro de estrangeiros na amostragem.

Quanto à motivação das visitas, o que prevalece é o banho de cachoeira. A motivação por conhecer ou tomar banho nas cachoeiras e poços naturais confirma-se quando $81 \%$ dos visitantes entrevistados consideram as fontes hídricas como o principal atrativo da trilha.

De forma geral, pode-se notar que, apesar de existirem informações sobre a visitação no PEIb, elas são pouco utilizadas como um instrumento na gestão. As formas atuais de coletar os dados ocupam quase todo o tempo dos monitores, que teoricamente deveriam dar ênfase ao trabalho de atendimento nas trilhas Isso os deixa retidos em escritório e dependentes da estrutura administrativa e de computadores para realizar o trabalho. As formas de manipular e arquivar os dados também dificultam sua utilização.

$\mathrm{Na}$ realidade, hoje a administração do PEIb carece de funcionários em número adequado, de recursos e principalmente do entendimento da importância do planejamento para as ações de visitação. Infelizmente, essa realidade também está presente em outros parques, conforme confirmam Robim et al. (2004):

No Brasil, as Unidades de Conservação sofrem com a falta de planejamento, de pessoal e de equipes qualificadas para a coordenação e implantação dos Programas de Manejo. Portanto, os estudos sobre os impactos da visitação e o manejo do Uso Público são escassos, bem como limitados principalmente, pelas dificuldades da aplicação de técnicas mais avançadas, as quais exigem informações científicas mais consistentes (Robim et al., 2004).

Nesse sentido, uma proposta simples e operacional, que visa otimizar os recursos e definir padrões de coleta de informação, apresenta-se como uma ferramenta bastante necessária à gestão.

\subsection{Seleção de indicadores de gestão da visitação no PEIb}

O estudo da visitação é um diagnóstico essencial à compreensão da dinâmica, de seus fluxos, características e, principalmente, dos conflitos que a presença de visitantes impõe em uma área protegida e insular. Essa etapa também é fundamental para a seleção de indicadores de gestão, pois para que sejam viáveis e eficazes devem ser consideradas as condições e os recursos espaciais, humanos, administrativos, técnicos e financeiros da instituição. Somente assim poderão identificar que condições serão monitoradas e quais meios deverão ser utilizados.

Os indicadores propostos para o PEIb foram baseados nas três importantes referências: o Bountîle adaptado para a Ilha de Port-Cros e Ilha de Porquerolles (Brigande Le Berre, 2007); 
os indicadores propostos pelo Manual de Turismo Responsável para Políticas Locais (WWF Brasil, 2004); e, o documento "Desenvolvendo indicadores para o manejo sustentável no uso de áreas protegidas por visitantes na Austrália” (Tongue et al., 2005).

Tabela 2. Panorama geral da visitação no Parque Estadual de Ilhabela (PEIb). (Tr. $=$ trilha)

\begin{tabular}{|c|c|c|c|c|c|}
\hline Onde & Quanto & Quando & Quem & O Que & Como \\
\hline $\begin{array}{l}\text { Estrada dos } \\
\text { Castelhanos }\end{array}$ & $\begin{array}{l}16.379 \\
17.226\end{array}$ & $\begin{array}{l}2010 \\
2009\end{array}$ & $\begin{array}{l}\text { Turistas; veranistas; comunidade } \\
\text { tradicional, residentes, esportistas }\end{array}$ & $\begin{array}{l}\text { Off Road, pedestres, } \\
\text { ciclistas, cavalo, } \\
\text { corrida de aventura, }\end{array}$ & $\begin{array}{l}71 \% \text { agências } \\
68 \% \text { agências } \\
\text { Clubes de off road } \\
\text { Particulares }\end{array}$ \\
\hline Tr. Água Branca & $\begin{array}{l}18.591 \\
7.972\end{array}$ & $\begin{array}{l}2010 \\
2009\end{array}$ & $\begin{array}{l}89 \% \text { adultos } \\
43 \% \text { 21 a } 30 \text { anos } \\
69 \% \text { turistas - navios } \\
18 \% \text { veranistas } \\
13 \% \text { residentes }\end{array}$ & $\begin{array}{l}\text { 98\% Lazer } \\
\text { Educação ambiental; } \\
\text { Cultos Religiosos; } \\
\text { Bird watching }\end{array}$ & $\begin{array}{l}\text { 55\% Família } \\
88 \% \text { Autoguiados }\end{array}$ \\
\hline Tr. Gato & $\begin{array}{l}40 \%-60 \% \\
\text { do Fluxo da } \\
\text { Estrada dos } \\
\text { Castelhanos }\end{array}$ & & $\begin{array}{l}\text { Comunidade tradicional, turistas, } \\
\text { grupos }\end{array}$ & $\begin{array}{l}\text { Captação de água; } \\
\text { lazer; treinamentos } \\
\text { de técnica vertical. }\end{array}$ & $\begin{array}{l}\text { 20\% Agências, } \\
\text { 80\%Autoguiados }\end{array}$ \\
\hline Tr. Baepi & $\begin{array}{l}146 \\
98\end{array}$ & $\begin{array}{l}2010 \\
2009\end{array}$ & $\begin{array}{l}48 \% \text { turistas } \\
35 \% \text { veranistas, adultos, jovens } \\
17 \% \text { moradores }\end{array}$ & $\begin{array}{l}86 \% \text { Lazer - } \\
\text { Caminhada; Caça; } \\
14 \% \\
\text { Trabalho/Estudo }\end{array}$ & $\begin{array}{l}50 \% \text { Amigos } \\
10 \% \text { Sozinhos } \\
59 \% \text { Autoguiados } \\
87 \% \text { particulares }\end{array}$ \\
\hline Tr. Três Tombos & $\begin{array}{l}3.535 \\
2.684\end{array}$ & $\begin{array}{l}2010 \\
2009\end{array}$ & $\begin{array}{l}10 \% \text { crianças } \\
19 \% \text { 41 a } 60 \text { - navios } \\
63 \% 21 \text { a } 40 \\
51 \% \text { turistas } 40 \% \text { veranistas }\end{array}$ & 98\% Lazer; & $\begin{array}{l}51 \% \text { Família } \\
37 \% \text { Amigos } \\
92 \% \text { Autoguiados }\end{array}$ \\
\hline Tr. Veloso & $\begin{array}{l}330 \\
563\end{array}$ & $\begin{array}{l}2010 \\
2009\end{array}$ & $\begin{array}{l}63 \% \text { turistas; } 25 \text { veranistas; } 12 \% \\
\text { moradores; } \\
\text { Adultos: } 1 \% \text { crianças }\end{array}$ & $\begin{array}{l}100 \% \text { Lazer; } \\
\text { rapel }\end{array}$ & $100 \%$ Autoguiados \\
\hline Tr. Bonete & 1.939 & 2010 & $\begin{array}{l}54 \% \text { turistas; } 43 \% \text { Veranistas; } 3 \% \\
\text { moradores. } \\
\text { Comunidade tradicional } \\
\text { Jovens e adultos }\end{array}$ & $\begin{array}{l}92 \% \text { Lazer; } \\
\text { Acesso à } \\
\text { comunidade; } \\
\text { pedestres, motos. }\end{array}$ & $\begin{array}{l}59 \% \text { Amigos } \\
8 \% \text { Companheiro } \\
98 \% \text { Autoguiados }\end{array}$ \\
\hline
\end{tabular}

A abordagem de multi-indicadores provê dados mais quantitativos para atributos específicos, refletindo as condições de um local utilizado para recreação (Leung e Marion, 1998). O monitoramento desses indicadores pressupõe a elaboração de protocolos de coleta de dados, os quais devem indicar: o tipo e período (dia/mês e horário) da coleta, quem irá realizá-la, como será (questionários, contagem, contato com outra instituição) e qual será o local. A construção dos protocolos, além de facilitar a padronização da coleta de informações, possibilitará a organização do trabalho em campo, estabelecendo escalas de trabalho, saídas a campo, material necessário, previsão de gastos, entre outros (Brigand e Le Berre, 2007), sendo um instrumento importante para a administração geral do parque.

Para a construção dos indicadores da gestão da visitação do PEIb apresentados no Quadro 1, foram utilizados os seguintes critérios: usos e usuários, condições climáticas, bemestar dos moradores, segurança, perfil dos visitantes, bem-estar do visitante, comportamento do visitante, certificação e gestão institucional.

Quadro 1. Protocolo de monitoramento dos indicadores de gestão da visitação no Parque Estadual de Ilhabela.

\begin{tabular}{|l|l|l|}
\hline \multicolumn{1}{|c|}{ Indicador } & \multicolumn{1}{c|}{ Parâmetro } & \multicolumn{1}{c|}{ Protocolo de coleta } \\
\hline $\begin{array}{l}\text { Visitação nas } \\
\text { trilhas }\end{array}$ & $\begin{array}{l}\text { Número de visitantes nas trilhas e } \\
\text { Centro de Visitantes }\end{array}$ & $\begin{array}{l}\text { Dado de coleta: número de visitantes; } \\
\text { Modo: contagem do número de pessoas no retorno do } \\
\text { passeio*; }\end{array}$ \\
\hline
\end{tabular}




\begin{tabular}{|c|c|c|}
\hline & & $\begin{array}{l}\text { Local: entrada dos atrativos terrestres oficiais, incluindo } \\
\text { Centro de Visitantes; } \\
\text { Frequência**: finais de semana de Natal e Ano Novo; no } \\
\text { Feriado de Carnaval; em um fim de semana comum entre abril } \\
\text { e junho e agosto e novembro. Em um feriado prolongado } \\
\text { (setembro, abril, novembro); em dois dias seguidos de semana, } \\
\text { entre abril e junho e agosto e novembro. Em um final de } \\
\text { semana da Semana de Vela. No horário entre } 8 \mathrm{~h} \text { e } 18 \mathrm{~h} \text {. }\end{array}$ \\
\hline Visitação Náutica & Número de embarcações/ pessoas & $\begin{array}{l}\text { Dado de coleta: número de embarcações e pessoas; } \\
\text { Modo: Contagem in loco das embarcações/pessoas; coleta dos } \\
\text { registros das marinas e operadoras de mergulho***. } \\
\text { Local: saco do Sombrio, praia da Figueira, ilhas da Vitória e } \\
\text { dos Búzios; marinas colaboradoras e operadoras de mergulho. } \\
\text { Frequência: sempre que houver saída de barco**** por algum } \\
\text { programa do PEIb; mensalmente. }\end{array}$ \\
\hline $\begin{array}{l}\text { Desembarques na } \\
\text { Ilha }\end{array}$ & $\begin{array}{l}\text { Número de passageiros que } \\
\text { desembarcaram na balsa }\end{array}$ & $\begin{array}{l}\text { Dado de coleta: número de pessoas; } \\
\text { Modo: Contagem por meio dos registros da Dersa. } \\
\text { Frequência: mensalmente. }\end{array}$ \\
\hline \multirow{3}{*}{$\begin{array}{l}\text { Incidência solar e } \\
\text { temperatura }\end{array}$} & $\mathrm{N}^{\circ}$ de dias de sol & $\begin{array}{l}\text { Dado de coleta: número dias sem chuva; } \\
\text { Modo: análise dos dados. } \\
\text { Local: http://tempo.cptec.inpe.br/ } \\
\text { Frequência: mensalmente }\end{array}$ \\
\hline & $\mathrm{N}^{\circ}$ de dias de chuva & $\begin{array}{l}\text { Dado de coleta: número dias com chuva; } \\
\text { Modo: análise dos dados. } \\
\text { Local: http://tempo.cptec.inpe.br/ } \\
\text { Frequência: mensalmente }\end{array}$ \\
\hline & Índice pluviométrico & $\begin{array}{l}\text { Dado de coleta: Índice pluviométrico; } \\
\text { Modo: análise dos dados. } \\
\text { Local: http://tempo.cptec.inpe.br/ } \\
\text { Frequência: mensalmente }\end{array}$ \\
\hline $\begin{array}{l}\text { Força e direção } \\
\text { dos ventos }\end{array}$ & $\mathrm{N}^{\mathrm{o}}$ de ventos fortes & $\begin{array}{l}\text { Dado de coleta: força e direção dos ventos; } \\
\text { Modo: análise dos dados. } \\
\text { Local: http://tempo.cptec.inpe.br/ } \\
\text { Frequência: mensalmente }\end{array}$ \\
\hline \multirow{2}{*}{$\begin{array}{l}\text { Nível de } \\
\text { envolvimento da } \\
\text { população local }\end{array}$} & $\begin{array}{l}\% \text { moradores satisfeitos com a } \\
\text { visitação nas áreas do PEIb }\end{array}$ & $\begin{array}{l}\text { Dado de coleta: nível de satisfação. Ex: } \\
\text { Satisfeito/Insatisfeito/Indiferente } \\
\text { Modo: aplicação de } 150 \text { questionários de perfil do visitante no } \\
\text { retorno do passeio *****. } \\
\text { Local: Bonete, Castelhanos, População em geral (atores CTs). } \\
\text { Frequência: uma vez ao ano }\end{array}$ \\
\hline & $\begin{array}{l}\text { \% de população local nos atrativos } \\
\text { e eventos }\end{array}$ & $\begin{array}{l}\text { Dado de coleta: porcentagem de residentes nos atrativos e } \\
\text { eventos do PEIb; } \\
\text { Modo: análise dos dados de contagem de visitantes (terrestre e } \\
\text { náutica) } \\
\text { Frequência: a mesma da contagem. }\end{array}$ \\
\hline \multirow{3}{*}{$\begin{array}{l}\text { Nível de } \\
\text { participação da } \\
\text { população local no } \\
\text { comércio }\end{array}$} & $\begin{array}{l}\mathrm{N}^{\mathrm{o}} \text { de operadoras (receptivos) locais } \\
\text { que operam no parque, comparado } \\
\text { ao número total. }\end{array}$ & $\begin{array}{l}\text { Dado de coleta: número de operadoras locais que operam no } \\
\text { parque } \\
\text { Modo: análise das fichas de controle da Estrada dos } \\
\text { Castelhanos } \\
\text { Frequência: anualmente }\end{array}$ \\
\hline & $\begin{array}{l}\mathrm{N}^{\circ} \text { de Ilhabelenses/residentes há } \\
\text { mais de } 10 \text { anos, que trabalham } \\
\text { com turismo nessas operadoras } \\
\text { comparado ao número total }\end{array}$ & $\begin{array}{l}\text { Dado de coleta: número de ilhabelenses /residentes há mais de } \\
10 \text { anos que trabalham com turismo nessas operadoras. } \\
\text { Modo: cadastro das Agências no PEIb / Entrevistas. } \\
\text { Frequência: anualmente }\end{array}$ \\
\hline & $\begin{array}{l}\mathrm{N}^{\mathrm{o}} \text { de operadoras de mergulho local } \\
\text { que operam no parque comparado } \\
\text { ao total. }\end{array}$ & $\begin{array}{l}\text { Dado de coleta: número de operadoras locais que operam nas } \\
\text { áreas de APA Marinha, entorno marítimo do PEIb. } \\
\text { Modo: entrevista com representante das operadoras/ } \\
\text { Abordagem dos funcionários do PEIb, nas saídas de barco. } \\
\text { Frequência: anualmente }\end{array}$ \\
\hline \multirow{2}{*}{$\begin{array}{l}\text { Relevância das } \\
\text { ocorrências }\end{array}$} & $\begin{array}{l}\mathrm{N}^{\circ} \text { de ocorrências de resgates e } \\
\text { acidentes }\end{array}$ & $\begin{array}{l}\text { Dado de coleta: } \mathrm{N}^{\circ} \text { de ocorrências de resgates e acidentes } \\
\text { Modo: contagem por meio de livro de ocorrências a ser } \\
\text { implantado } \\
\text { Frequência: mensalmente }\end{array}$ \\
\hline & Natureza dos resgates e acidentes & $\begin{array}{l}\text { Dado de coleta: tipos de acidentes e resgates } \\
\text { Modo: análise do livro de ocorrências } \\
\text { Frequência: anualmente }\end{array}$ \\
\hline
\end{tabular}




\begin{tabular}{|c|c|c|}
\hline $\begin{array}{l}\text { Características do } \\
\text { visitante }\end{array}$ & $\begin{array}{l}\text { Faixa etária } \\
\text { Gênero } \\
\text { Origem }\end{array}$ & $\begin{array}{l}\text { Dado de coleta: faixa etária/ gênero/origem dos visitantes; } \\
\text { Modo: aplicação de } 150 \text { questionários de perfil do visitante no } \\
\text { retorno do passeio; durante o passeio para os visitantes de } \\
\text { atrativos náuticos no próprio local ou em marinas; } \\
\text { Local: entrada dos atrativos terrestres oficiais, incluindo } \\
\text { Centro de Visitantes } \\
\text { Frequência**: fins de semana de Natal e Ano Novo; no } \\
\text { Feriado de Carnaval; em um final de semana comum entre } \\
\text { abril e junho e agosto e novembro. Em um feriado prolongado } \\
\text { (setembro, abril, novembro); em dois dias seguidos de semana, } \\
\text { entre abril e junho e agosto e novembro. Em um fim de semana } \\
\text { da Semana de Vela. No horário entre } 8 \mathrm{~h} \text { e } 18 \mathrm{~h} \text {. }\end{array}$ \\
\hline \multirow{2}{*}{$\begin{array}{l}\text { Atividades } \\
\text { realizadas }\end{array}$} & Tipo de atividade /local & $\begin{array}{l}\text { Dado de coleta: atividades realizadas pelos usuários durante } \\
\text { as visitas nas trilhas/ náuticas. } \\
\text { Modo: aplicação de } 150 \text { questionários de perfil do visitante no } \\
\text { retorno do passeio; durante o passeio para os visitantes de } \\
\text { atrativos náuticos no próprio local ou em marinas; } \\
\text { Local: entrada dos atrativos terrestres oficiais, incluindo } \\
\text { Centro de Visitantes } \\
\text { Frequência**: fins de semana de Natal e Ano Novo; no } \\
\text { Feriado de Carnaval; em um final de semana comum entre } \\
\text { abril e junho e agosto e novembro. Em um feriado prolongado } \\
\text { (setembro, abril, novembro); em dois dias seguidos de semana, } \\
\text { entre abril e junho e agosto e novembro. Em um fim de semana } \\
\text { da Semana de Vela. No horário entre } 8 \mathrm{~h} \text { e } 18 \mathrm{~h} \text {. }\end{array}$ \\
\hline & Modo & $\begin{array}{l}\text { Dado de coleta: modo como realizou a visita (Autônomo } \\
\text { /operadora) } \\
\text { Modo: aplicação de } 150 \text { questionários de perfil do visitante no } \\
\text { retorno do passeio } \\
\text { Local: entrada dos atrativos terrestres oficiais, incluindo } \\
\text { Centro de Visitantes } \\
\text { Frequência**: fins de semana de Natal e Ano Novo; no } \\
\text { Feriado de Carnaval; em um final de semana comum entre } \\
\text { abril e junho e agosto e novembro. Em um feriado prolongado } \\
\text { (setembro, abril, novembro); em dois dias seguidos de semana, } \\
\text { entre abril e junho e agosto e novembro. Em um fim de semana } \\
\text { da Semana de Vela. No horário entre } 8 \mathrm{~h} \text { e } 18 \mathrm{~h} \text {. }\end{array}$ \\
\hline $\begin{array}{l}\text { Percepção da } \\
\text { visita }\end{array}$ & $\begin{array}{l}\text { Satisfação dos visitantes (terrestre) } \\
\text { sobre a sua visita }\end{array}$ & $\begin{array}{l}\text { Dado de coleta: nível de satisfação. Ex: } \\
\text { Satisfeito/Insatisfeito/Indiferente. } \\
\text { Modo: aplicação de } 150 \text { questionários de perfil do visitante, } \\
\text { no retorno do passeio } \\
\text { Local: entrada dos atrativos terrestres oficiais, incluindo } \\
\text { Centro de Visitantes } \\
\text { Frequência**: fins de semana de Natal e Ano Novo; no } \\
\text { Feriado de Carnaval; em um fim de semana comum entre abril } \\
\text { e junho e agosto e novembro. Em um feriado prolongado } \\
\text { (setembro, abril, novembro); em dois dias seguidos de semana, } \\
\text { entre abril e junho e agosto e novembro. Em um final de } \\
\text { semana da Semana de Vela. No horário entre } 8 \mathrm{~h} \text { e } 18 \mathrm{~h} \text {. }\end{array}$ \\
\hline $\begin{array}{l}\text { Percepção do nível } \\
\text { de visitação }\end{array}$ & $\begin{array}{l}\text { Satisfação sobre o número de } \\
\text { usuários do local visitado }\end{array}$ & $\begin{array}{l}\text { Item avaliado, atualmente, no monitoramente de impactos. } \\
\text { Sugestão: integrar em um único modo de coleta }\end{array}$ \\
\hline \multirow[t]{2}{*}{$\begin{array}{l}\text { Comportamento } \\
\text { do visitante }\end{array}$} & $\begin{array}{l}\text { Relato do comportamento } \\
\text { indesejável de outros visitantes }\end{array}$ & $\begin{array}{l}\text { Dado de coleta: relato do comportamento indesejável de } \\
\text { outros visitantes } \\
\text { Modo: aplicação de } 150 \text { questionários de perfil do visitante no } \\
\text { retorno do passeio / Registros de reclamações (por email, livro } \\
\text { de visitantes ou relato de funcionários) } \\
\text { Local: entrada dos atrativos terrestres oficiais, incluindo } \\
\text { Centro de Visitantes } \\
\text { Frequência: fins de semana de Natal e Ano Novo; no Feriado } \\
\text { de Carnaval; em um fim de semana comum entre abril e junho } \\
\text { e agosto e novembro. em um feriado prolongado (setembro, } \\
\text { abril, novembro); em dois dias seguidos de semana, entre abril } \\
\text { e junho e agosto e novembro. Em um final de semana da } \\
\text { Semana de vela. No horário entre } 8 \mathrm{~h} \text { e } 18 \mathrm{~h} / \text { mensalmente }\end{array}$ \\
\hline & $\begin{array}{l}\text { Nível de conhecimento das regras } \\
\text { de visitação do parque pelos } \\
\text { visitantes }\end{array}$ & $\begin{array}{l}\text { Dado de coleta: nível de conhecimento das regras de visitação } \\
\text { do parque pelos visitantes } \\
\text { Modo: aplicação de } 150 \text { questionários de perfil do visitante no }\end{array}$ \\
\hline
\end{tabular}




\begin{tabular}{|c|c|c|}
\hline & & $\begin{array}{l}\text { retorno do passeio / Registros de reclamações (por email, livro } \\
\text { de visitantes ou relato de funcionários) } \\
\text { Local: entrada dos atrativos terrestres oficiais, incluindo } \\
\text { Centro de Visitantes; } \\
\text { Frequência: fins de semana de Natal e Ano Novo; no Feriado } \\
\text { de Carnaval; em um final de semana comum entre abril e } \\
\text { junho e agosto e novembro. Em um feriado prolongado } \\
\text { (setembro, abril, novembro); em dois dias seguidos de semana, } \\
\text { entre abril e junho e agosto e novembro. Em um fim de semana } \\
\text { da Semana de Vela. No horário entre } 8 \mathrm{~h} \text { e } 18 \mathrm{~h} / \text { mensalmente }\end{array}$ \\
\hline & Relatório das infrações & $\begin{array}{l}\text { Dado de coleta: número de ocorrências de infrações } \\
\text { relacionada à visitação } \\
\text { Modo: contagem por meio de livro de ocorrências a ser } \\
\text { implantado; Relato de funcionários } \\
\text { Frequência: mensalmente }\end{array}$ \\
\hline \multirow[t]{2}{*}{$\begin{array}{l}\text { Responsabilidade } \\
\text { socioambiental }\end{array}$} & $\begin{array}{l}\mathrm{N}^{\circ} \text { de empresas certificadas ou em } \\
\text { processo de certificação }\end{array}$ & $\begin{array}{l}\text { Dado de coleta: número de empresas que operam } \\
\text { comercialmente no PEIb certificada ou em algum processo de } \\
\text { certificação (Cadastur, ABNT, certificação municipal, caso } \\
\text { haja) } \\
\text { Modo: contagem por meios indiretos. Ex: site cadasturAnálise } \\
\text { do cadastro no PEIb; Entrevista com as empresas } \\
\text { Frequência: anualmente }\end{array}$ \\
\hline & $\begin{array}{l}\text { Códigos empresariais voluntários } \\
\text { de responsabilidade socioambiental }\end{array}$ & $\begin{array}{l}\text { Dado de coleta: existência de códigos empresariais } \\
\text { voluntários de responsabilidade socioambiental; (Ex: termos } \\
\text { de conduta, carta parque) } \\
\text { Modo: averiguação } \\
\text { Frequência: anualmente }\end{array}$ \\
\hline \multirow{2}{*}{$\begin{array}{l}\text { Participação na } \\
\text { gestão }\end{array}$} & $\begin{array}{l}\text { Porcentagem de entidades } \\
\text { interessadas em assuntos de turismo } \\
\text { participando da gestão e dos } \\
\text { conselhos } \\
\text { Implantados; }\end{array}$ & $\begin{array}{l}\text { Dado de coleta: porcentagem de entidades interessadas em } \\
\text { assuntos de turismo participando da gestão. } \\
\text { Modo: contagem de membros titulares e suplentes. } \\
\text { Local: câmaras Técnicas de Ecoturismo e Estrada dos } \\
\text { Castelhanos; Conselho Municipal de Turismo; GG65 } \\
\text { Frequência: anualmente }\end{array}$ \\
\hline & $\begin{array}{l}\text { Porcentagem da presença em } \\
\text { reuniões das entidades participantes } \\
\text { perante o total; }\end{array}$ & $\begin{array}{l}\text { Dado de coleta: porcentagem da presença em reuniões das } \\
\text { entidades participantes perante o total; } \\
\text { Modo: contagem de presenças por meio das listas de presenças } \\
\text { dos fóruns } \\
\text { Local: Câmaras Técnicas de Ecoturismo e Estrada dos } \\
\text { Castelhanos; Conselho Municipal de Turismo; GG65 } \\
\text { Frequência: anualmente }\end{array}$ \\
\hline Regulamentação & $\begin{array}{l}\text { Porcentagem de normas e } \\
\text { deliberações de interesse aprovadas } \\
\text { nos conselhos e no legislativo frente } \\
\text { ao total proposto; }\end{array}$ & $\begin{array}{l}\text { Dado de coleta: porcentagem de normas e deliberações de } \\
\text { interesse aprovadas nos conselhos e no legislativo frente ao } \\
\text { total proposto } \\
\text { Modo: contagem } \\
\text { Local: ata das reuniões } \\
\text { Frequência: anualmente }\end{array}$ \\
\hline \multirow{2}{*}{$\begin{array}{l}\text { Parcerias e } \\
\text { Convênios }\end{array}$} & $\begin{array}{l}\text { Número de parcerias formalizadas } \\
\text { entre o parque e atores locais; }\end{array}$ & $\begin{array}{l}\text { Dado de coleta: número de parcerias formalizadas entre o } \\
\text { parque e atores locais } \\
\text { Modo: averiguação } \\
\text { Frequência: anualmente }\end{array}$ \\
\hline & $\begin{array}{l}\text { Número de convênios/parcerias } \\
\text { firmados com universidades e } \\
\text { ONGs; }\end{array}$ & $\begin{array}{l}\text { Dado de coleta: número de convênios/parcerias firmados com } \\
\text { universidades e ONGs } \\
\text { Modo: averiguação } \\
\text { Frequência: anualmente }\end{array}$ \\
\hline \multirow[t]{2}{*}{ Planejamento } & $\begin{array}{l}\text { Número de propostas estabelecidas } \\
\text { no Plano de Manejo e outros; e } \\
\text { alcançadas no prazo; }\end{array}$ & $\begin{array}{l}\text { Dado de coleta: número de propostas estabelecidas no Plano } \\
\text { de Manejo e outros instrumentos, alcançadas; e alcançadas no } \\
\text { prazo } \\
\text { Modo: contagem } \\
\text { Frequência: anualmente }\end{array}$ \\
\hline & $\begin{array}{l}\text { Número de projetos previstos e em } \\
\text { andamento de modo satisfatório. }\end{array}$ & $\begin{array}{l}\text { Dado de coleta: número de projetos previstos e em andamento } \\
\text { de modo satisfatório } \\
\text { Modo: contagem } \\
\text { Frequência: anualmente }\end{array}$ \\
\hline
\end{tabular}

*O ideal é que o controle seja feito integralmente, como na Estrada dos Castelhanos. Como não é possível, devido à falta de estrutura e recursos, sugere-se fazer por amostragem, em períodos de maior e menor fluxo. O método Bountîle utiliza aparelhos chamados Éco-compteurs, instalados na entrada das trilhas do Parque Nacional de Port- 
Cros, para fazer a contagem de visitantes. De tempos em tempos os agentes do parque, equipados com um aparelho portátil, recolhem as informações por meio da transferência de dados. Em um primeiro momento pode ser um investimento alto, mas em longo prazo seu custo $\mathrm{x}$ benefício pode ser bastante recompensador.

** A frequência sugerida, assim como os outros itens, devem ser flexíveis e alterados de acordo com as possibilidades de monitorá-los.

*** O ideal é que todas as marinas e operadoras de mergulho sejam envolvidas no processo, possivelmente em forma de parcerias. Caso não seja possível, sugere-se manter as parcerias com aquelas que colaboraram com este estudo;

**** Em 2010 o PEIb adquiriu uma embarcação. Geralmente é utilizada pelos programas de Proteção e Interação Socioambiental, mediante calendário programado ou emergências. Desde que planejado, é possível conciliar as contagens e entrevistas náutica durante essas saídas.

*****O número de questionários pode ser alterado de acordo com as necessidades e possibilidades de aplicação.

\section{CONSIDERAÇÕES FINAIS}

Este trabalho indicou que, em grande parte, os estudos sobre a visitação em espaços protegidos ficam restritos à mensuração dos impactos gerados e à proposição de medidas de manejo. Poucos são os que propõem ferramentas de gestão da visitação a partir de um sistema que compreenda a gama de variáveis que a prática em uma área protegida requer. $\mathrm{O}$ planejamento e a gestão das atividades recreativas, adequados à realidade e características do parque, além de estritamente necessários, precisam ser apropriados, não só pelos funcionários do programa de uso público, mas por todos, principalmente pelos responsáveis pela gestão da unidade.

A participação da população local nesses processos é fundamental para que se evitem e se resolvam os conflitos entre os diferentes interesses de uso das áreas e seu objetivo de conservação. Acredita-se que o uso de indicadores voltados à gestão da visitação pode ser uma ferramenta prática e eficiente a ser incorporada nos planos de manejo, iniciando-se com o estudo da visitação e indicando diretrizes de monitoramento e avaliação para curto, médio e longo prazos. Para tanto, é fundamental que sejam testados em diferentes locais e que seus resultados sejam publicados, fomentando o debate na comunidade científica, mas principalmente que esses resultados cheguem aos responsáveis pela gestão dessas áreas como propostas executáveis.

\section{REFERÊNCIAS}

BRASIL. Ministério do Meio Ambiente. Sistema Nacional de Unidades de Conservação da Natureza - SNUC. Lei ${ }^{\circ}$ 9.985, de 18 de julho de 2000; Decreto $n^{\circ} 4.340$, de 22 de agosto de 2002. 5. ed. Brasília, 2004.

BRASIL. Ministério do Meio Ambiente. Instituto Chico Mendes de Biodiversidade. Unidades de Conservação. Brasília, 2009. Disponível em: <http//www.icmbio.gov.br/portal>. Acesso em: 20 fev. 2010.

BRIGAND, L.; LE BERRE, S. Joint construction and appropriation of indicators by users, managers and scientists: the case study of Port-Cros and Porquerolles tourist frequentation observatory. Journal of Sustainable Development, v. 10, n. 1/2, p.139$160,2007$.

INSTITUTO CHICO MENDES DE CONSERVAÇÃO DA BIODIVERSIDADE - ICMBio. Número de visitantes em parques nacionais. 2009. Disponível em: http://www.icmbio.gov.br. Acesso em: 22 set. 2009. 
KABASHIMA, Y.; MAGRO, T. C. Caracterização atual do monitoramento de impactos de visitação em Parques do Estado de São Paulo. Olam: Ciência \& Tecnologia, v. 11, p. 107-123, 2011.

LEUNG, Y.; MARION, J. L. Survey of whitewater recreation impacts along five West Virginia Rivers. Final Report. Blacksburg: U. S. Department of the Interior; U.S. Geological Survey; Virginia Tech Cooperative Park Studies Unit, 1998. 98 p.

ROBIM, M. J.; FONTES, M. A.; CAVALHEIRO, F. Determinação da capacidade de carga da trilha da Praia do Sul no Parque Estadual da Ilha Anchieta: uma aplicação do método de Cinfuentes. In: SANTOS, J. E. dos; CAVALHEIRO, F.; RODRIGUES PIRES, J. S.; OLIVEIRA, C. H.; RODRIGUES PIRES, A. M. Z. C. (Org.). Faces da polissemia da paisagem: ecologia, planejamento e percepção. São Carlos: RiMa, 2004. 408p.

SÃO PAULO (Estado). Secretaria do Meio Ambiente. Unidade de Conservação da Natureza/Secretaria do Meio Ambiente do Estado de São Paulo, Fundação Florestal. In: OLIVEIRA, L. R (Org.); NEVES, A. S. et al. (Textos), Unidades de conservação da natureza. São Paulo, 2009. 103p. (Cadernos de Educação Ambiental)

SÃO PAULO (Estado). Secretaria do Meio Ambiente. Plano de fiscalização integrada nas áreas protegidas do Estado de São Paulo. São Paulo, 2012. 26p.

STIGLIANO, B.V.; CÉSAR, P. A. B. Capacidade de carga, VAMP, LAC e outros métodos de gerenciamento da visitação: reflexões sobre a aplicação do VAMP no turismo. In: COSTA, CASTILHO, N. M.; NEIMAN, Z.; COSTA, V. C. (Org.). Pelas trilhas do ecoturismo. São Carlos: [s.n.], 2008.

T4 CONSUlTORIA EM TURISMO LTDA. Plano gestor de turismo de Ilhabela. 2004. Disponível em: http://www.t4.tur.br/ilhabela/. Acesso em: 22 set. 2009.

TAKAHASHI, L. Y. Monitoramento de indicadores de impactos nas trilhas e percepção dos visitantes em Unidades de Conservação. In: CONGRESSO NACIONAL DE PLANEJAMENTO E MANEJODE TRILHAS, 1., 2006, Rio de Janeiro. Anais... Rio de Janeiro: [s.n.], 2006. 1 CD-ROM.

TONGE, J.; MOORE, S.; HOCKINGS, M.; WORBOYS, G.; BRIDLE, K. Developing indicators for the sustainable management of visitor use of protected areas in Australia.CRC for Sustainable Tourism. Gold Coast, 2005. 39p. Disponível em: <http://researchrepository.murdoch.edu.au/1945/1/ developing_indicators.pdf>. Acesso em: 20 ago. 2011.

WWF BRASIL. Turismo responsável: manual para políticas públicas. Brasília, 2004. 220p. 